$11-11-2014$

\title{
Olfactory Acuity in Chronic Migraine: A Cross-Sectional Study.
}

\author{
Alexander C Whiting \\ Michael J. Marmura \\ Thomas Jefferson University \\ Sarah E Hegarty \\ Thomas Jefferson University
}

Scott W. Keith

Thomas Jefferson University, Clinical Pharmacology and Experimental Therapeutics

Follow this and additional works at: https://jdc.jefferson.edu/neurologyfp

Part of the Neurology Commons

Let us know how access to this document benefits you

\section{Recommended Citation}

Whiting, Alexander C; Marmura, Michael J.; Hegarty, Sarah E; and Keith, Scott W., "Olfactory Acuity in Chronic Migraine: A Cross-Sectional Study." (2014). Department of Neurology Faculty Papers. Paper 77.

https://jdc.jefferson.edu/neurologyfp/77

This Article is brought to you for free and open access by the Jefferson Digital Commons. The Jefferson Digital Commons is a service of Thomas Jefferson University's Center for Teaching and Learning (CTL). The Commons is a showcase for Jefferson books and journals, peer-reviewed scholarly publications, unique historical collections from the University archives, and teaching tools. The Jefferson Digital Commons allows researchers and interested readers anywhere in the world to learn about and keep up to date with Jefferson scholarship. This article has been accepted for inclusion in Department of Neurology Faculty Papers by an authorized administrator of the Jefferson Digital Commons. For more information, please contact: JeffersonDigitalCommons@jefferson.edu. 
Olfactory Acuity in Chronic Migraine: a Cross-sectional Study

ABSTRACT:

Objective: To measure olfactory acuity in chronic migraine subjects, at baseline and on migraine days, and compare to age and sex-matched controls.

Background: Olfactory impairment is common in neurological disorders. While smell hypersensitivity has been established with chronic migraine, olfactory acuity has not been well studied.

Methods: We recruited 50 subjects with chronic migraine from the Jefferson Headache Center and 50 age and sex-matched controls. Using the University of Pennsylvania Smell Identification Test (UPSIT), a validated test of olfaction, olfactory acuity was measured at baseline and during a migraine for subjects, and compared to controls at baseline and at home 2 weeks later. All subjects were additionally screened for odor sensitivity and allodynia.

Results: The mean UPSIT score for migraine subjects was 34.5 on non-migraine days and 34.7 on migraine days [mean difference $=-0.4,95 \% \mathrm{CI}(-1.3,0.6) \mathrm{p}=0.45$ ]. Controls had a mean of 35.9 and 36.1 for each test day [mean difference $=-0.1,95 \% \mathrm{CI}(-0.9,0.7)$ $p=0.87]$. On average, migraineurs performed worse than their matched control counterparts in both test sittings [test $1: \mathrm{p}=0.047$; test $2: \mathrm{p}=0.01$ ]. The great majority of subjects were allodynic (42/50) compared with only 9 of 50 controls, and the majority of subjects (41/50) found more than 1 listed odor to be bothersome, compared with only 10/50 controls. On non-migraine days 18/48 chronic migraine subjects had abnormal olfaction and on migraine days 14/42 had abnormal olfaction, compared with only $9 / 50$ controls who had abnormal olfaction on their first UPSIT. 
Conclusions: While chronic migraine patients do not appear to have a significant change in olfactory acuity between migrainous and non-migrainous periods, they do appear to be more likely to have abnormal olfactory acuity at baseline compared to age and sexmatched controls.

\section{INTRODUCTION:}

Patients with chronic migraine (CM) often display significant disability, as well hypersensitivity to specific stimuli such as light and sound. ${ }^{1}$ Hypersensitivity to sensory stimuli such light and sound are both diagnostic features of migraine, ${ }^{2}$ but migraine patients are also much more likely to be bothered by odors than other persons. In fact, osmophobia may be a more specific symptom in differentiating migraine from other headache disorders. ${ }^{3,4}$ Discomfort due to olfactory stimuli is most prominent during acute migraine, but may persist between attacks. ${ }^{5}$

Olfactory impairment is a common symptom of other neurologic disorders such as schizophrenia and Parkinson's disease. This may be related to damage of dopaminergic, serotonergic and cholinergic systems. ${ }^{6,7}$ It is possible that olfactory hypersensitivity in CM patients is related to this dopaminergic dysfunction. While olfactory sensitivity has been demonstrated in patients with migraine, olfactory acuity in episodic migraine subjects in between attacks is similar to age and sex-matched controls with a standardized testing of olfaction. ${ }^{8}$ This includes our previous study of olfaction using the University of Pennsylvania Smell Identification Test (UPSIT). ${ }^{9}$ In these episodic migraine subjects, olfactory acuity decreased in many patients during acute migraine and even after successful acute treatment. Based on these results, we hypothesized that CM patients would have greater olfactory deficits on both migraine days and less severe days. 


\section{METHODS:}

We recruited 50 patients from the Jefferson Headache Center clinic from June - August 2011 meeting criteria for CM ages 18-65 as defined by the International Classification of Headache Disorders (ICHD-2R). ${ }^{10}$ As indicated by the diagnosis, subjects were required to have at least 8 migraine days a month (or days with acute migraine medication use) and at least 15 days a month of headache. Additionally, the subjects had to meet the migraine criteria of having headaches accompanied by either nausea and/or vomiting or both photophobia and phonophobia. We obtained formal approval for this study from the Institutional Review Board at Thomas Jefferson University and all subjects and controls provided informed consent. We excluded subjects or controls with a history of significant headache trauma, nasal or sinus disease, and neurologic disorders such as Parkinson disease, dementia or multiple sclerosis. We excluded patients regularly taking sedating medications during acute attacks, such as opioids. Given that subjects had to take the UPSIT on both more severe migraine days and non-migraine days, we included patients with some fluctuation between migraine and non-migraine days. Subjects who met the inclusion criteria completed a questionnaire to determine disease diagnosis and history, attain demographic information, and verify medications. No particular education level was obtained. We used the questionnaire to determine the patients' subjective olfactory characteristics, asking subjects how they would describe their smell function during a migraine day using the forced answers "improves", "stays the same", or "gets worse". We asked patients if they found one or more odors bothersome using a forced answer question bank, recording the patient as being sensitive to odors if they answered "most 
always" or "always" for any of the odors presented. We established the presence of allodynia during migraine using a validated questionnaire which screens for the presence of unpleasant sensations of skin in response to routine activities such as combing hair, wearing clothes or heat and cold exposure. ${ }^{11}$

After completing the questionnaire, subjects and controls took the UPSIT, a standardized, validated test for olfaction. ${ }^{12}$ The test involves 40 odorants embedded in "scratch and sniff" microcapsules, each with a four answer forced choice question about the identity of the odorant. A score of 35 or greater is considered normal for women, and a score of 34 or greater is considered normal in men. ${ }^{12}$ A change in UPSIT score of greater than 3 points is considered clinically significant for the purposes of this study. Subjects were then given a second UPSIT test to take home with them, to be taken 2 weeks later during a migraine at home. If a subject took the UPSIT on the initial visit during a migraine attack, they were required to repeat the UPSIT during a non-migraine day at least 2 weeks after the initial visit. The subjects were asked to take the non-migraine day test on a day when they were completely free of any symptoms of their migraines or headaches, and the timing of this was left to the determination of the subject. Subjects were required to mail or drop off the second test at the Jefferson Headache Center.

For comparison, 50 controls were recruited from the hospital, community, and friends and family of patients. Controls were age ( \pm 2 years) and sex-matched and had no history of migraine. Controls were excluded if they displayed any disability from headache as determined by score of greater than "0" on the Migraine Disability Assessment (MIDAS) Questionnaire. ${ }^{13}$ Controls completed a similar questionnaire as given to the subjects about olfactory sensitivity, function and allodynia, and then completed an UPSIT test in the 
Jefferson Headache Center. Controls were then given an additional UPSIT test, which they completed at home 2 weeks later and sent back to the clinic.

\section{Statistical Analysis:}

Baseline characteristics were compared between matched pairs of subjects and controls using McNemar's or Bowker's tests of symmetry for categorical data, as appropriate, and

paired t-tests for continuous data. Similarly, paired t-tests were used to compare matched subject and controls scores and scores from between test sittings. All tests are two-tailed with statistical significance set at $\alpha=0.05$. Analyses were performed in SAS 9.3 (SAS Institute Inc., Cary, NC).

The number of subjects was determined before the study based on previous studies using UPSIT in various neurological disorders which assumed an effect size of 3 points for the parameter of group differences in olfaction, and based on the funding available for this study.

\section{RESULTS:}

We recruited $50 \mathrm{CM}$ subjects and age and sex-matched controls, although one of the 10 male cases, a 43 year-old, was matched to a 42 year-old female control. CM subjects had a mean age of 42 with a range of $18-63$, while controls had a mean age of 41.7 with a range of 20-64. The great majority of subjects were allodynic (42/50) compared with only 9 of 50 controls, and the majority of subjects (41/50) found more than 1 listed odor to be bothersome, compared with only 10/50 controls. Table 1 lists demographic features of the two groups. A majority (28/50) of subjects had aura, but 22/50 did not. Visual aura was the most common type. Twenty-two subjects predicted increased olfactory acuity during 
migraine days, while only 4 predicted decreased olfaction and the remainder anticipated no change or did not respond.

All controls and 48/50 subjects took the UPSIT at the initial visit. Forty of the $50 \mathrm{CM}$ subjects completed the UPSIT twice as did 47/50 controls. The mean UPSIT score for migraine subjects was 34.5 on non-migraine days and 34.7 on migraine days [mean difference $=-0.4,95 \% \mathrm{CI}(-1.3,0.6) \mathrm{p}=0.45]$. Controls had a mean of 35.9 and 36.1 for each test day [mean difference $=-0.1,95 \% \mathrm{CI}(-0.9,0.7) \mathrm{p}=0.87]$. On average, migraineurs performed slightly worse than their matched control counterparts in both test sittings [test 1: mean difference $=-1.5(-3.0,0.0) \mathrm{p}=0.047$; test 2 : mean difference $=-1.5$ $(-2.7,-0.3) \mathrm{p}=0.01]$. On non-migraine days $18 / 48 \mathrm{CM}$ subjects had abnormal olfaction and on migraine days 14/42 had abnormal olfaction (McNemar's test, $p=1.00$ ). Nine of 50 controls had abnormal olfaction on the first UPSIT, and 10 of 47 had abnormal scores on follow-up testing. Four CM subjects had a decrease of olfaction of greater than 3 points on migraine compared to non-migraine days, while two had a greater than 3 point increase in UPSIT scores on migraine days. Two controls had a decreased UPSIT score of greater than 3 points on the second test and one had an increase of greater than 5 points. (Table 2) Of the 8 non-allodynic subjects with CM, 1 had abnormal olfaction and 1 did not complete the during-migraine UPSIT.

\section{CONCLUSION:}

Olfaction and sensitivity to odors is a significant problem in migraine, but olfactory acuity is generally normal in persons with episodic migraine. However, there is increasing evidence that for some persons olfactory acuity is affected by migraine. Hirsh, in a study predating existing migraine classification, found that about $18 \%$ of migraine 
subjects were hyposmic or anosmic based on Pyridine odor threshold testing. ${ }^{14}$ Although our previously described study found that persons with episodic migraine had normal olfaction, a significant number had decreased olfaction during acute attacks. ${ }^{9}$ In this study of CM subjects, a much larger proportion had abnormal olfaction but interestingly the difference between migraine and non-migraine days was not significant.

When considering a change of greater than 3 points to be statistically significant, 4 patients with CM had significantly lower scores during migraine, and 2 had improved scores. In CM subjects, their olfactory acuity does not appear to change on migraine days of increased severity. This lack of change in olfaction suggests a more ingrained problem, and may correlate with central sensitization. The majority of CM subjects in this study had allodynia $(42 / 50,84 \%)$ but no patient without allodynia had abnormal olfaction. This suggests poor olfaction could be a relatively specific measure for central sensitization in migraine, much like in degenerative diseases.

Increases in parasympathetic tone, which can manifest as tearing, swelling or congestion during migraine, is associated with engorgement of nasal turbinates. ${ }^{15}$ Fluctuations in nasal engorgement are an overall indicator of autonomic tone ${ }^{16}$ and correlate with measures such as rapid-eye movement sleep patterns ${ }^{17}$ and cognitive abilities ${ }^{18}$. It is possible that $\mathrm{CM}$ produces these changes in autonomic tone, resulting in decreased ability of odorants to successfully reach smell receptors, which would have negatively affected performance on the UPSIT.

Abnormal olfaction in CM could be related to the known phenomenon of olfactory distortions ${ }^{19}$ related to migraine. Functional neuroimaging data in chronic pain states that demonstrate changes in activation of basal ganglia structures with loss of dopaminergic 
input and decreased connectivity to the prefrontal cortex ${ }^{20}$. This relates to another interesting issue, which is each patient's personal sense of olfactory acuity during acute migraine days in CM. Among CM subjects a significant minority (22/50, 44\%) reported improved olfaction on migraine days, while only 2 patients $(8 \%)$ felt their sense of smell worsened and the majority reported no change $(26 / 50,52 \%)$. In our patients with episodic migraine, subjects who reported improvement in olfactory acuity during migraine did not actually improve. In CM subjects the results were mixed with 10 patients correctly predicting improved olfaction and 7 with lower scores during migraine. This difference was not statistically significant but was a contrast with our episodic migraine group. 


\section{REFERENCES:}

1. Beckmann YY, Secil Y, Kendir AL, Basoglu M. Chronic migraine: a prospective descriptive clinical study in a headache center population. Pain Pract 2009;9:380-4.

2. Headache Classification Committee, Olesen J, Bousser MG, Diener HC, Dodick D, First M, Goadsby PJ, Göbel H, Lainez MJ, Lance JW, Lipton RB, Nappi G, Sakai F, Schoenen J, Silberstein SD, Steiner TJ. New appendix criteria open for a broader concept of chronic migraine. Cephalalgia 2006;26:742-6.

3. Corletto E, Dal Zotto L, Resos A, Tripoli E, Zanchin G, Bulfoni C, Battistella PA. Cephalalgia. Osmophobia in juvenile primary headaches 2008;28:825-31

4. Vingen JV, Sand T, Stovner LJ. Sensitivity to various stimuli in primary headaches: a questionnaire study. Headache 1999;39:552-8.

5. Kelman L. Osmophobia and taste abnormality in migraineurs: a tertiary care study. Headache 2004;44:1019-23.

6. Double KL, Rowe DB, Hayes M, Chan DK, Blackie J, Corbett A, Joffe R, Fung VS, Morris J, Halliday GM. Identifying the pattern of Olfactory Deficits in Parkinson Disease Using the Brief Smell Identification Test. Arch Neurol 2003;60:545-549

7. Kohler CG, Moberg PJ, Gur RE, O'Connor MJ, Sperling MR, Doty RL. Olfactory Dysfunction in Schizophrenia and Temporal Lobe Epilepsy, Neuropsychiatry Neurpsychol Behav Neurol 2001;14:83-8

8. Saisu A, Tatsumoto M, Hoshiyama E, Aiba S, Hirata K. Evaluation of olfaction in patients with migraine using an odour stick identification test. Cephalalgia 2011;31:1023 
9. Marmura MJ, Anjum MW. Olfactory Acuity in Migraine During and Between Attacks. Presented at the American Academy of Neurology Annual Meeting in April 2011. Honolulu HI.

10. Headache Classification Subcommittee of the International Headache Society. The International Classification of Headache Disorders, 2nd edition. Cephalalgia 2004; 24:44-54.

11. Ashkenazi A, Silberstein S, Jakubowski M, Burstein R. Improved identification of allodynic migraine patients using a questionnaire. Cephalalgia 2007;27:325-9.

12. Doty RL, Shaman P, Kimmelman CP, Dann MS. University of Pennsylvania Smell Identification Test: a rapid quantitative olfactory function test for the clinic. Laryngoscope 1984;94:176-8

13. Stewart WF, Lipton RB, Dowson AJ, Sawyer J. Development and testing of the Migraine Disability Assessment (MIDAS) Questionnaire to assess headache-related disability. Neurology 2001;56:S20-8.

14. Hirsch AR. Olfaction in migraine. Cephalalgia 1998;18:360.

15. Jones $\mathrm{N}$. The nose and paranasal sinuses physiology and anatomy. Adv Drug Deliv Rev 2001;51:5-19

16. Werntz DA, Bickford RG, Bloom FE, Shannahoff-Khalsa DS. Alternating cerebral hemispheric activity and the lateralization of autonomic nervous function. Hum Neurobiol 1983;2:39-43.

17. Goldstein L, Stoltzfus NW, Gardocki JF. Changes in interhemispheric amplitude relationships in the EEG during sleep. Physiol Behav 1972;8:811-5. 
18. Klein R, Pilon D, Prosser S, Shannahoff-Khalsa D. Nasal airflow asymmetries and human performance. Biol Psychol 1986;23:127-37.

19. Hong SC, Holbrook EH, Leopold DA, Hummel T. Distorted olfactory perception: a systematic review. Acta Otolaryngol 2012;132:S27-31.

20. Borsook D, Upadhyay J, Chudler EH, Becerra L. A key role of the basal ganglia in pain and analgesia--insights gained through human functional imaging. Mol Pain $2010 ; 6: 27$ 
Table 1. Descriptive summary of group characteristics.

\begin{tabular}{|c|c|c|c|c|c|}
\hline & \multicolumn{2}{|c|}{$\begin{array}{l}\text { Migraineurs } \\
(\mathrm{n}=\mathbf{5 0})\end{array}$} & \multicolumn{2}{|c|}{$\begin{array}{l}\text { Controls } \\
(\mathrm{n}=\mathbf{5 0})\end{array}$} & \multirow{2}{*}{$\begin{array}{l}\mathbf{p} \\
0.16\end{array}$} \\
\hline Age, mean (range) & \multicolumn{2}{|c|}{$42.0(18-63)$} & \multicolumn{2}{|c|}{$41.7(20-64)$} & \\
\hline Sex, n $(\%)$ & & & & & 0.32 \\
\hline Female & 40 & $(80.0)$ & 41 & (82.0) & \\
\hline Male & 10 & $(20.0)$ & 9 & (18.0) & \\
\hline Race, $\mathbf{n}(\%)$ & & & & & 0.90 \\
\hline White & 46 & $(92.0)$ & 41 & $(82.0)$ & \\
\hline Black & 1 & $(2.0)$ & 3 & $(6.0)$ & \\
\hline Asian & 1 & $(2.0)$ & 3 & $(6.0)$ & \\
\hline Hispanic & 2 & $(4.0)$ & 3 & $(6.0)$ & \\
\hline Height (in inches), mean + std & 66. & -3.85 & 66. & +4.00 & 0.97 \\
\hline Weight (in lbs), mean + std & 163 & 34.9 & 175 & 45.3 & 1.00 \\
\hline BMI, mean + std & 26.3 & -4.74 & 28 & +7.78 & 0.13 \\
\hline Allodynia, n (\%) & & & & & $<0.01$ \\
\hline Yes & 42 & $(84.0)$ & 9 & (18.0) & \\
\hline No & 8 & (16.0) & 41 & $(82.0)$ & \\
\hline
\end{tabular}

\section{Migraineurs}

$(\mathbf{n}=\mathbf{5 0})$

\section{Controls}

$(\mathbf{n}=\mathbf{5 0})$ p

Odors Bothersome, n (\%) $<0.01$ 
Yes

No
$41 \quad$ (82.0)

9

(18.0)
$10 \quad(20.0)$

$40 \quad(80.0)$ 
Table 2. Olfaction summary of outcomes

\begin{tabular}{|c|c|c|c|}
\hline & $\begin{array}{l}\text { Migraineurs } \\
(\mathbf{n}=\mathbf{5 0})\end{array}$ & $\begin{array}{l}\text { Controls } \\
(\mathbf{n}=\mathbf{5 0})\end{array}$ & $\begin{array}{l}\text { Paired } \\
\text { Difference } \\
\text { (Migraine- } \\
\text { Control) } \\
\text { Mean }(95 \% \mathrm{CI})\end{array}$ \\
\hline \multicolumn{3}{|l|}{$\begin{array}{l}\text { Non-migraine day (CM) } \\
\text { or baseline (control) score }\end{array}$} & \\
\hline mean & 34.5 & 35.9 & $-1.5(-3.0,0.0)$ \\
\hline Abnormal, \% & $18 / 48,(37.5 \%)$ & $9 / 50,(18.0 \%)$ & $\mathrm{p}=0.047$ \\
\hline \multicolumn{3}{|l|}{ Migraine Day or 2nd } & \\
\hline \multicolumn{3}{|l|}{ UPSIT Score } & \\
\hline mean & 34.7 & 36.1 & $-1.5(-2.7,-0.3)$ \\
\hline abnormal, \% & $14 / 42,(33.3 \%)$ & $10 / 47,(21.3 \%)$ & $\mathrm{p}=0.01$ \\
\hline Test Difference (2nd - 1st) & $-0.4(-1.3,0.6)$ & $-0.1(-0.9,0.7)$ & \\
\hline Mean $(95 \% \mathrm{CI})$ & $\mathrm{p}=0.45$ & $\mathrm{p}=0.87$ & \\
\hline
\end{tabular}

